\title{
TEXTURE ANALYSIS OF QUARTZ IN A GRANITE MYLONITE BY EBSP-ORIENTATION IMAGING MICROSCOPY
}

\author{
A. PEARSON, F. HEIDELBACH ${ }^{\dagger}$ and H.R. WENK* \\ Department of Geology and Geophysics, University of California, Berkeley, \\ CA 94720-4767, USA
}

(Received 20 November 1996)

The crystallographic preferred orientation (texture) of the quartz phase in a mylonitic leucogranite from the Santa Rosa mylonite zone was investigated using automated analysis of electron backscattering patterns (EBSP) in the scanning electron microscope (SEM). The separation of the quartz diffraction patterns from patterns of other constituents (feldspar, mica, etc.) in this polymineralic rock was achieved using an image quality parameter. The quartz phase displays a texture typical for high temperature mylonites ( $c$-axis maximum in the intermediate strain direction). The misorientation distribution between next neighbors is dominated by Dauphiné twins.

Keywords: Quartz; EBSP; Misorientation distribution; Polyphase materials

\section{INTRODUCTION}

The measurement of crystallographic preferred orientation (texture) with bulk diffraction methods is considerably limited for low symmetry and polyphase materials by the resolution and overlap of diffraction peaks. Particularly the texture analysis of polymineralic granitic rocks, which are of great interest to structural geologists, due to their abundance in crystal deformation zones, is complicated by the

\footnotetext{
* Corresponding author.

${ }^{\dagger}$ Present address: ESRF, B.P. 220 F-38043 Grenoble, France.
} 
low symmetry of its main constituents like mica and feldspar. The problem of peak overlap has partially been overcome by the use of neutron diffraction which generally has a higher resolution in $2 \Theta$ (Drechsler et al., 1988; Wenk and Pannetier, 1990) and allows for better peak deconvolution, or new approaches with profile analysis (Lutterotti et al., 1997). However, the use of neutron diffraction is limited by the small number of available facilities. A different approach is the measurement of individual crystal orientations either with optical methods (U-stage) or by electron diffraction.

Automated analysis of EBSPs or OIM (orientation imaging microscopy) was originally developed to study metals (Adams et al., 1993; Wright, 1992; Schmidt and Olesen, 1989). Since then it has also been applied to minerals with trigonal symmetry (Kunze et al., 1993; 1994). Unlike traditional techniques for measuring textures (X-ray and neutron diffraction), this method links lattice orientation of single crystals with the microstructure of a sample.

The present study, conducted at Los Alamos National Laboratory's Center for Material Science, is the first application of automated EBSP analysis to a complex polyphase rock. An image quality (IQ) parameter is used in order to separate orientation measurements of quartz from measurements of other minerals in a sample of mylonitic leucogranite.

EBSPs are generated in a scanning electron microscope (SEM) when a stationary electron beam (diameter of $\sim 0.2 \mu \mathrm{m}$ ) penetrates the surface of a crystal. Backscattered electrons which strike crystallographic planes are preferentially diffracted according to Bragg's law and form cones of radiation resulting in a pattern known as EBSP. Each band in an EBSP represents a specific lattice plane (hkl). Band directions are a function of crystal orientation. Band widths are a function of interplanar spacing. Therefore, the geometrical arrangement of bands can be used to index a pattern (assign hkl's to bands) and to determine the lattice orientation of a local region.

Schmidt and Olesen (1989) proposed a method for digitally analyzing EBSPs. Using this method, Wright and Adams (1992) introduced a completely automated system which requires no intervention from the operator once a data collection run begins. A computer controls translations of a $x-y$ stage, a camera records the EBSP which is processed and digitized. The recognition of the diffraction bands in the pattern is achieved by a Hough transform, which converts lines 
(bands) into single maxima (Illingworth and Kittler, 1988). The computer indexes the pattern, calculates orientation angles and determines an image quality parameters that depends on the contrast of the EBSP (Wright, 1993).

Regardless of pattern quality, the computer will try to index the EBSP. In order to assess the accuracy of computer indexing, two parameters are used: an image quality (IQ) parameter and a match quality (MQ) parameter. The IQ parameter evaluates the clarity of the digitized pattern. If a Hough transform contains only a few broad maxima, a low IQ is assigned. Conversely a sharp pattern with many Hough maxima has a high IQ.

The MQ parameter evaluates the similarity between the SEM generated EBSP and the computer indexed EBSP. Once determined, the MQ parameter can be used to remove measurements with a poor match. Unfortunately, the TexSEM Laboratories software system used in this study did not provide MQ parameters.

\section{MATERIAL AND EXPERIMENTAL PROCEDURES}

\section{Sample Description}

The sample used in this study, PC374, is a mylonitic leucogranite from the Palm Canyon Formation in the Santa Rosa mylonite zone (SRMZ) in southern California. Mylonitization has been associated with shear movements and the emplacement of the Peninsular Ranges batholith in the late Cretaceous (Erskine and Wenk, 1985; Simpson, 1984). The leucogranite, primarily composed of quartz and altered feldspar, has a strong mylonitic foliation and lineation. Small amounts of biotite are found along the perimeter of high-angle grain boundaries. The microstructure of this sample (Fig. 1) is represented by large coherent feldspar grains (1-2 mm "clasts") and elongated quartz grains which are flattened parallel to the foliation characteristic of the so-called 'granulite petrographic texture'.

\section{Sample Preparation}

Three perpendicular circular sections, $2.5 \mathrm{~cm}$ in diameter and $0.5 \mathrm{~cm}$ thick (Fig. 2), were cut normal to the foliation and parallel to the 


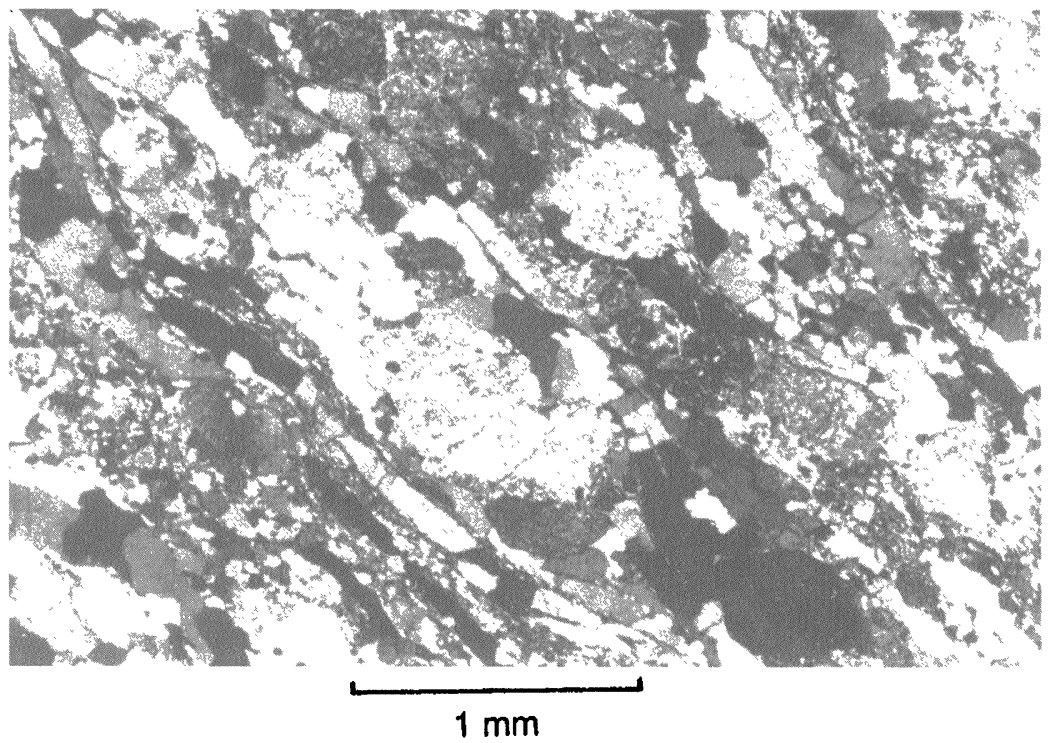

FIGURE 1 Transmitted light photomicrograph of PC374 in thin section, illustrating the microstructure. Crossed polars. Diagonal platelets are mainly quartz, large rounded grains are feldspar.

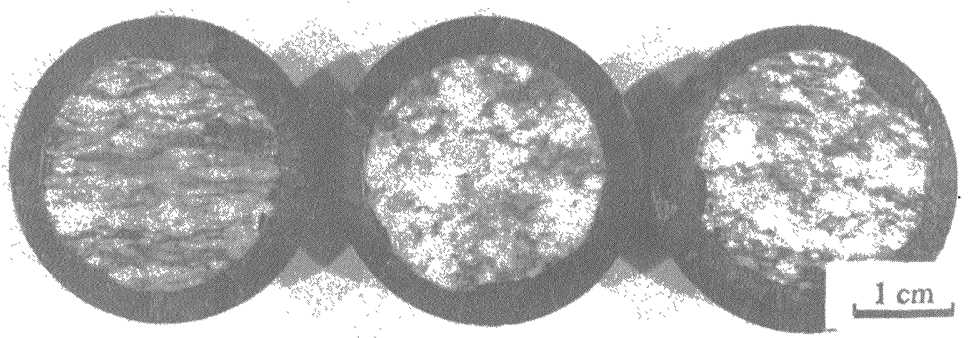

FIGURE 2 Photograph of three circular samples 374A, 374B and 374C, used for the EBSP analysis. 

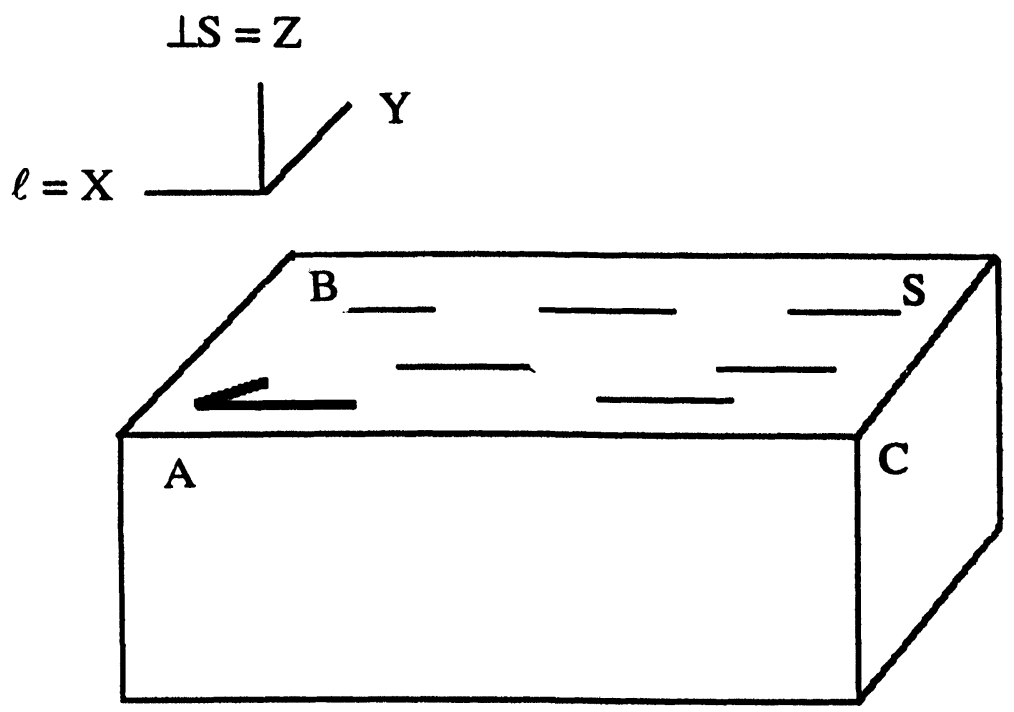

FIGURE 3 Schematic diagram showing how sections A, B and C were cut in relation to lineation $(l=X)$ and foliation $S$, and defining the geological fabric coordinates $X, Y$ and $Z$.

lineation (A), parallel to the foliation (B), and perpendicular to both the foliation and the lineation (C) (Fig. 3). The samples were mechanically ground using diamond paste (smallest grain size $0.25 \mu \mathrm{m}$ ) and enclosed in an epoxy mount. Surface damage induced by grinding was removed by polishing the samples for $24 \mathrm{~h}$ with a Buehler vibratory polisher in a solution of $0.05 \mu \mathrm{m}$ colloidal silica. The surface of the epoxy was painted with carbon in order to reduce charging. After SEM measurements, sections were etched with hydrofluoric acid (HF) in order to increase the contrast for observations in reflected light.

\section{Experimental Settings}

Charging effects in the SEM were reduced by using a low accelerating voltage of $12 \mathrm{kV}$. Each of the three samples was run at least twice. Measured areas ranged from $1 \mathrm{~mm}^{2}$ to $1 \mathrm{~cm}^{2}$ and were scanned in a hexagonal grid with an average step-size of $25 \mu \mathrm{m}$, resulting in at least 6000 measured points per run. Table I provides information on individual runs. 
TABLE I Summary of information on individual OIM EBSP experiments

\begin{tabular}{lccc}
\hline Sample number & $\begin{array}{c}\text { Dimensions } \\
\text { (microns) }\end{array}$ & $\begin{array}{c}\text { Step-width } \\
\text { (microns) }\end{array}$ & $\begin{array}{c}\text { Total number of } \\
\text { measurement }\end{array}$ \\
\hline $374 \mathrm{~A}-2$ & $4,500 \times 1,000$ & 15 & 23,439 \\
$374 \mathrm{~A}-3$ & $3,000 \times 2,000$ & 15 & 31,278 \\
$374 \mathrm{~A}-4$ & $10,000 \times 7,000$ & 50 & 38,961 \\
$374 \mathrm{~B}-1$ & $1,000 \times 1,000$ & 10 & 11,658 \\
$374 \mathrm{~B}-2$ & $5,000 \times 500$ & 20 & 9,591 \\
$374 \mathrm{C}-1$ & $10,000 \times 10,000$ & 50 & 46,316 \\
$374 \mathrm{C}-2$ & $4,000 \times 3,000$ & 20 & 34,887 \\
$374 \mathrm{C}-4$ & $1,000 \times 4,000$ & 20 & 6,042 \\
$374 \mathrm{C}-5$ & $4,000 \times 15,000$ & 20 & 14,034 \\
\hline
\end{tabular}

\section{RESULTS}

\section{Microstructures}

Microstructural maps were constructed from orientation measurements. Figure 4(a) is a grain boundary map of a single quartz grain. Each point is compared to its six neighbors on the hexagonal grid. If the orientation difference (misorientation) between two measurements is greater than $10^{\circ}$, a black line is drawn between the two points. In the same figure, points with an IQ greater than 35 are highlighted in black. Notice that the majority of black lines, separating cells, are concentrated outside of the gray area, i.e. not in quartz. This is because in areas with low IQ values (presumably feldspar and mica grains) the solutions found by the algorithm are more or less random, producing large misorientations between data points. The boundaries outlining hexagonal cells can therefore not be interpreted as high angle grain boundaries. The test is important because it shows that the indexing algorithm does not interpret a feldspar EBSP as a quartz orientation.

The sample area can also be imaged as a function of IQ value (Fig. 4(b)), assigning each cell different shades of gray for different IQ values. In this figure, cells with an IQ greater than 35 are white. Darker gray shades indicate lower IQ values. Comparison between Fig. 4(a) and (b) shows that the orientation imaging technique maps out reliably the contiguous quartz grain with IQ $>35$.

The same technique is applied to a large sample area in section $\mathrm{C}$ (Fig. 5(b)). The image contrast (IQ) map corresponds closely with the microstructure, photographed with a reflected light microscope (Fig. 5(a)). 

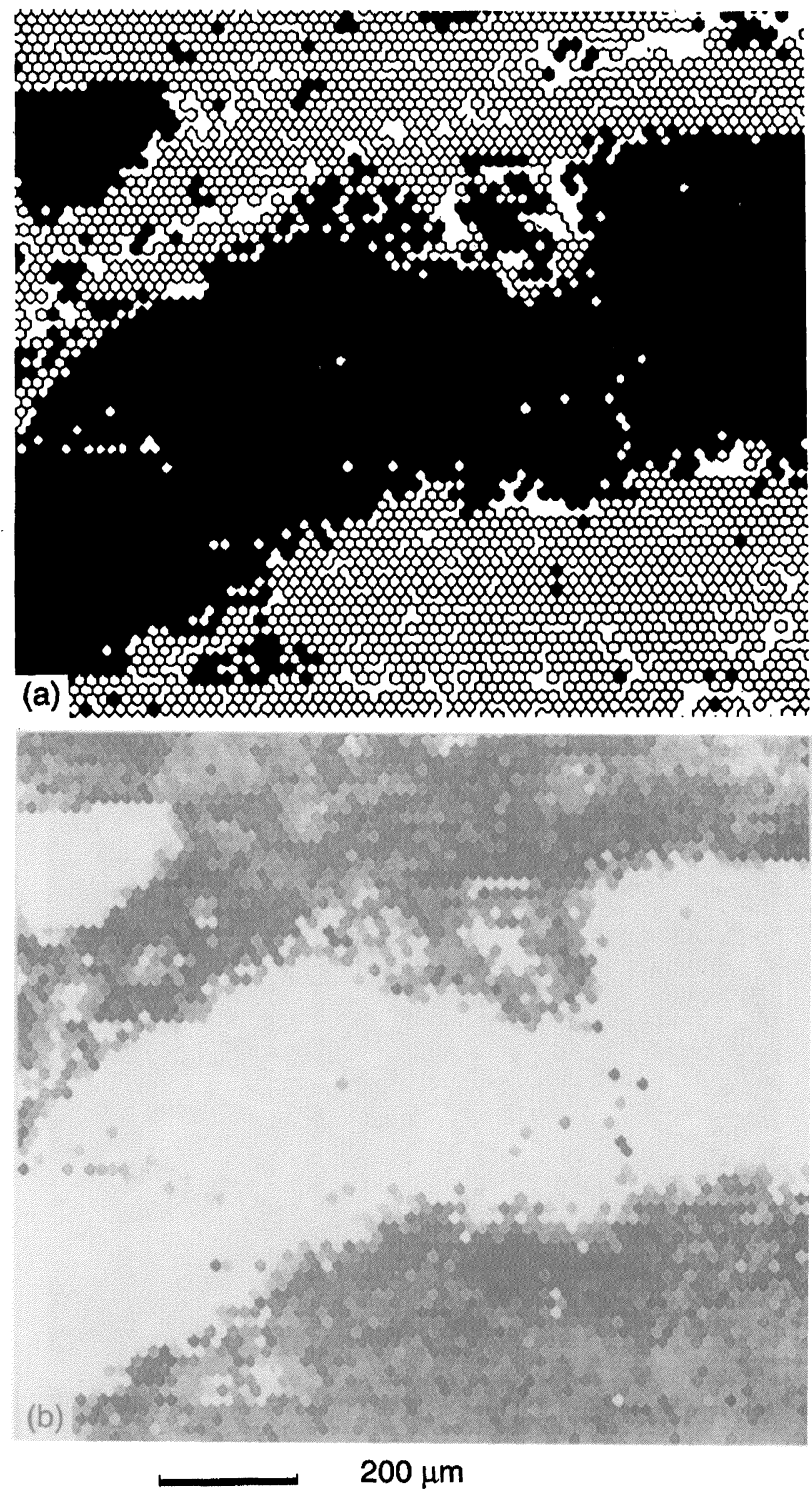

FIGURE 4 Single quartz grain in a matrix of other minerals. (a) Grain boundary map. Measured cells with an IQ greater than 35 are highlighted in gray. Dark lines are assigned if misorientations between adjacent cells are greater than $10^{\circ}$. The hexagonal cell pattern in areas of low IQ is due to a random assignment of orientations if the EBSP pattern does not match with quartz. (b) Contrast map of the grain shown in (a). This time cells with an IQ greater than 35 are colored white. Shades of gray darken as IQ value decreases. 


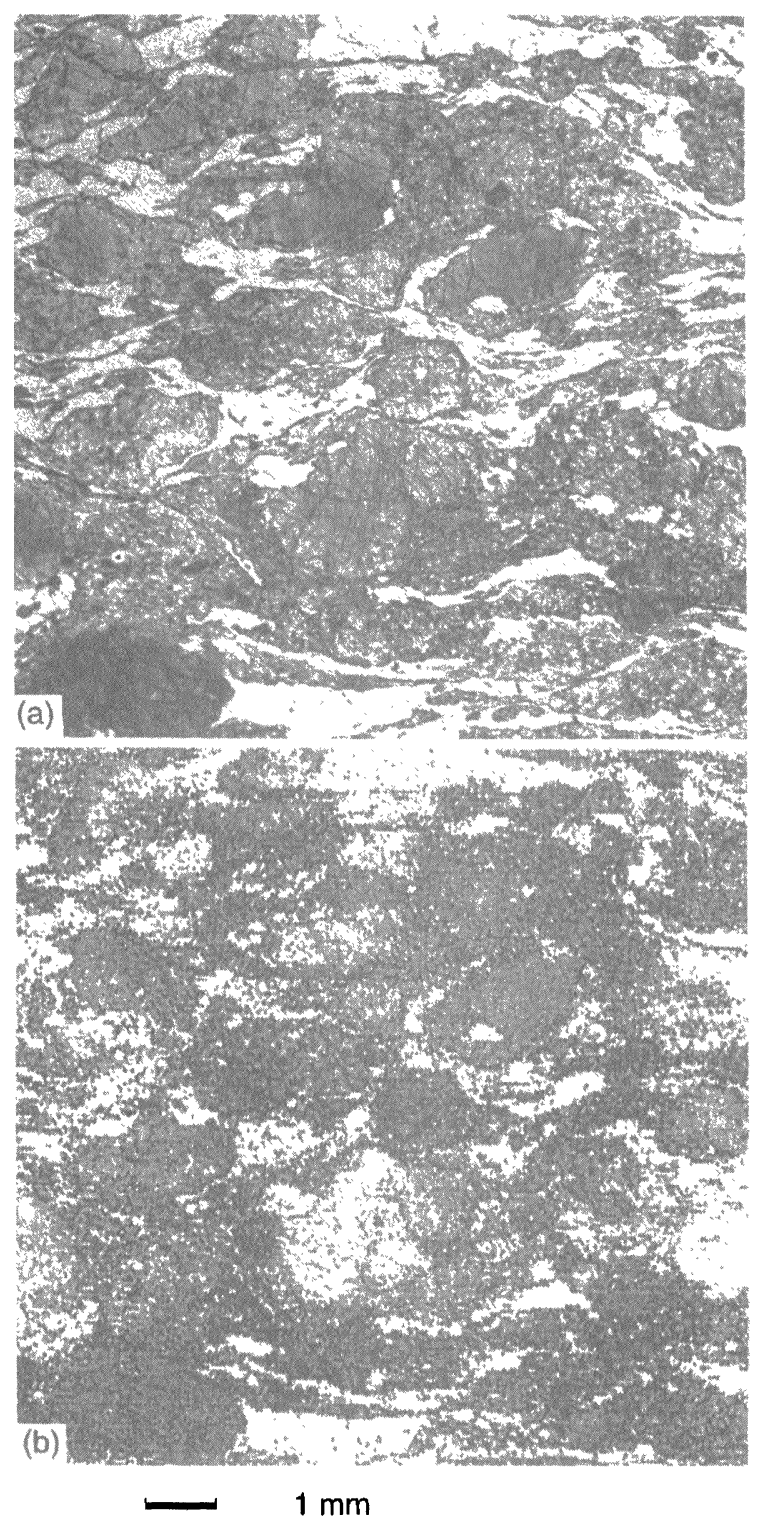

FIGURE 5 Large area of sample 374C-1. (a) Reflected light micrograph of the sample after etching. Crossed polars. White, flattened crystals parallel to the horizontal foliation are quartz. (b) Contrast map. Cells with an IQ greater than 35 are colored white. Shades of gray darken as IQ value decreases. There is a good correlation between high IQ and quartz. 


\section{Textures}

Measurements with a low IQ value were rejected from orientation calculations. All other individual orientation measurements from the three sections were rotated into the same orientation ( $\mathrm{C}$ section, normal to foliation and lineation). Orientations were then entered into boxes in the ODF using discrete methods (Matthies and Vinel, 1993) and assigning to each orientation a Gaussian of $15^{\circ}$ full width at halfmaximum (FWHM). From the ODF, pole figures for various lattice planes were calculated with programs in the BEARTEX package (Wenk et al., 1996). Eight pole figures were calculated for each section and for a combination of the three sections (Figs. 6 and 7). The combination ODF was also smoothed by applying a Gauss bell of $10^{\circ}$ FWHM. Figure 6 displays pole figures for poles (hkil) with hexagonal symmetry (i.e. pyramids (hh $\overline{2 \mathrm{k}} 1$ ) and prisms) and Fig. 7 displays those with trigonal symmetry, separating positive rhombs $(\mathrm{h} 0 \overline{\mathrm{h}} 1)$ and negative rhombs $(0 \mathrm{~h} \overline{\mathrm{h}} 1)$. The lineation $X$ is in the center of the pole figure, $Y$ is perpendicular to the lineation in the foliation plane, and $Z$ indicates the normal to the foliation plane.

Observe the good agreement between the pole figures from the three sections. (0001) pole figures consistently display slightly asymmetric $c$ axis maxima which lie preferentially in the foliation plane and perpendicular to the lineation. Pole figures from first-order prisms (1010) and second-order prisms $(10 \overline{2} 0)$ exhibit girdles which trend $\mathrm{N}-\mathrm{S}$. Maxima are located at approximately $60^{\circ}$ intervals along the girdle, corresponding to the angle between $a$-axes. Notice that maxima on this girdle in $(10 \overline{1} 0)$ pole figures correspond to minima in $(10 \overline{2} 0)$ pole figures, and vice versa. A similar relationship holds for pairs of positive and negative rhombs, such as $(10 \overline{1} 0)(01 \overline{1} 1)$ and (1012) (0112) in Fig. 7.

\section{Misorientations}

The orientation difference (misorientation) between adjacent crystallites is expressed with the statistical misorientation distribution in axisangle space (Fig. 8). A sharp maximum is observed in the (0001) direction at $\omega=55-60^{\circ}$, corresponding to the Dauphiné twin law which is a $180^{\circ}\left(60^{\circ}\right)$ rotation around [0001]. 


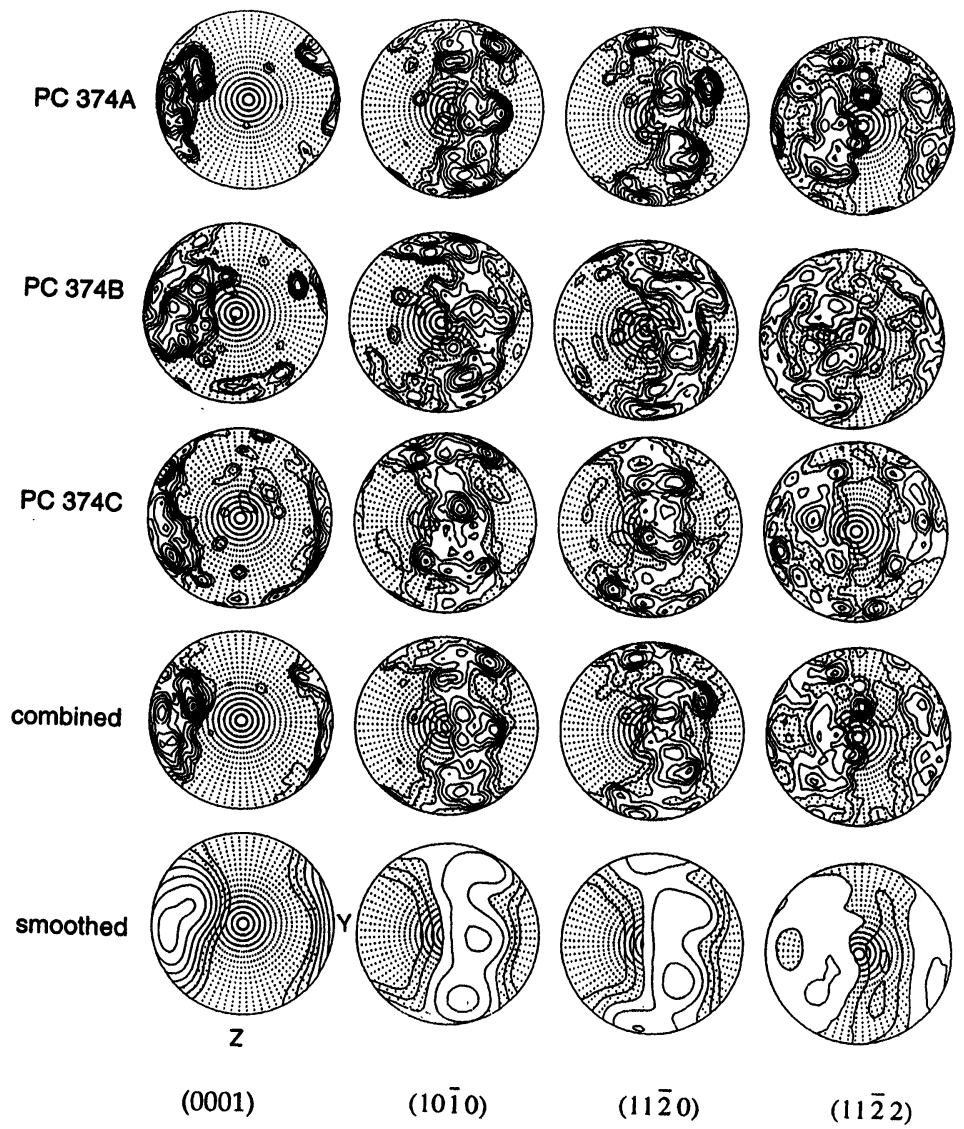

FIGURE 6 Pole figures for sample PC 374, recalculated from the discrete ODF, for lattice planes displaying hexagonal symmetry. Equal area projection. Logarithmic contours are $0.5,0.7,1.0,1.4,2.0,2.8,4.0,5.6,8.0,11.3,16.0,22.6,32.0$ m.r.d. Areas with less than 1 m.r.d. are stippled. $Z$ is normal to the foliation, the lineation $(X)$ is in the center of the pole figure. Shown are pole figures for individual sections (all rotated into the $\mathrm{C}$ orientation), the combined pole figures and the combined smoothed pole figures.

\section{DISCUSSION}

The results of texture analysis in this mylonitic leucogranite agree with results from earlier neutron diffraction experiments on granitic rocks from Palm Canyon (Wenk and Pannetier, 1990). The texture pattern is 


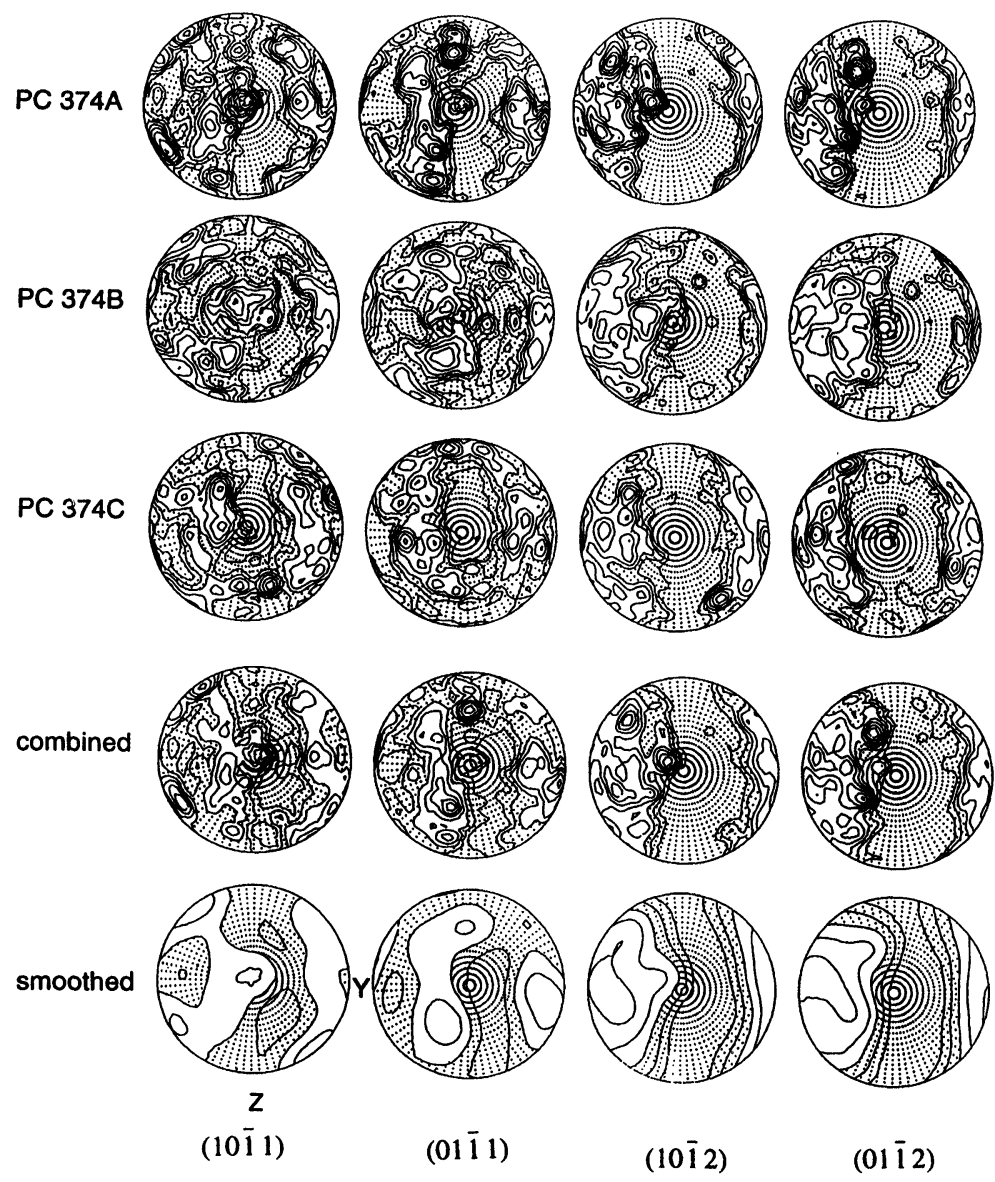

FIGURE 7 Pole figures for sample PC 374, recalculated from the discrete ODF, for lattice planes displaying trigonal symmetry with separation of positive and negative rhombs. Equal area projection. Logarithmic contours are 0.5, 0.7, 1.0, 1.4, 2.0, 2.8, 4.0, 5.6, 8.0, 11.3, 16.0, 22.6, 32.0 m.r.d. Areas with less than 1 m.r.d. are stippled. $Z$ is normal to the foliation, the lineation $(X)$ is in the center of the pole figure. Shown are pole figures for individual sections (all rotated into the $\mathrm{C}$ orientation), the combined pole figures and the combined smoothed pole figures.

also similar to previously documented quartz textures in quartzite mylonites with an asymmetric $c$-axis double maximum in the plane of foliation and at a high angle to the lineation (e.g. Helming et al., 1994; Schmid and Casey, 1986). Rather than an $a$-axis maximum (1120) parallel to the lineation we observe a concentration of (1010). 

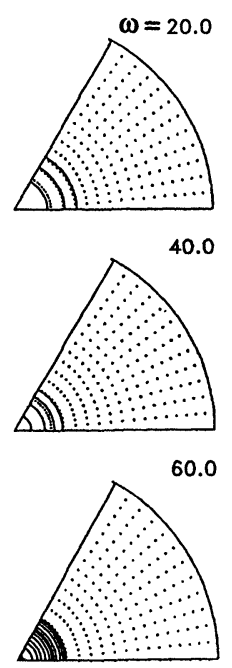

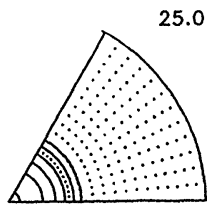

45.0

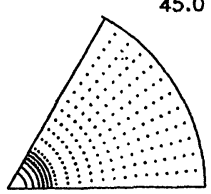

65.0



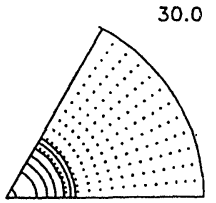

50.0

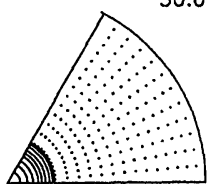

70.0

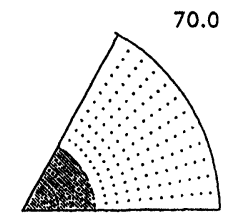

(0001)
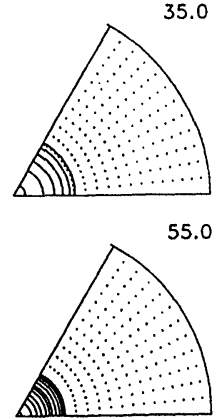

(10̄̄0)

FIGURE 8 Misorientation distribution between neighboring cells shown in axis-angle $(\omega)$ space. Equal area projection. $\omega$-sections in $5^{\circ}$ intervals. Logarithmic contours as in the previous figures. The strong concentration at (0001) for $\omega=60^{\circ}$ is due to Dauphine twinning. Sections below $\omega=20^{\circ}$ are not shown because they are below the lowest contour.

It has been suggested that this texture is generated by recrystallization (Helming et al., 1994). According to models, quartz textures with $c$-axis maxima at high angles to the direction of maximum compression may form during dynamic recrystallization (Jessell and Lister, 1990; Wenk et al., 1989; 1997; Wenk, 1994). Unfortunately, experimental studies have so far been unable to produce this texture in the laboratory (Gleason et al., 1993).

The results of the misorientation distribution display a sharp maximum at $\omega=55-60^{\circ}$ (Fig. 7). This angle represents the 2-fold rotation around the $c$-axis which produces Dauphiné twins. An earlier study by Kunze et al. (1993) used automated analysis of EBSPs to reveal Dauphiné twins and image the location of twin boundaries in a naturally recrystallized quartzite. Dauphiné twins cannot be observed with conventional light microscopy. They have been documented as mechanical twins in experimentally deformed quartzites (Tullis and Tullis, 1972). They also form during a cooling phase transition from hexagonal $\beta$-quartz to trigonal $\alpha$-quartz $\left(573^{\circ} \mathrm{C}\right.$ at atmospheric 
pressure) in quartzite (Barber and Wenk, 1991). Considering the geologic history of this metamorphic sample, Dauphiné twins are attributed to mechanical or thermal stresses.

The results of this study also demonstrate that OIM-EBSP can be used to reliably determine the texture in polymineralic rocks. The IQ factor can be applied to discriminate between different phases. In our case the sample polishing technique preferentially prepared quartz for generating EBSPs. The agreement between the contrast map (Fig. 5(b)) and the photomicrograph (Fig. 4(a)) is remarkable. Quartz grains (mainly colored white in both figures), whether elongated stringers, included clasts or large grains, can be easily distinguished from the surrounding material in the sample. Additionally, subtleties such as grain boundaries are not lost on the contrast map. For example, the large quartz grain at the bottom of the image is cut by a grain boundary which appears in both the photograph and the map.

However, the IQ mapping is not foolproof for phase identification. The IQ limit picked for each measurement is somewhat arbitrary and there are a couple of feldspar grains that do show high IQ values. One is located along the right border of the photograph and the other is directly to its left. However, the wrong solutions assigned to the feldspar or mica patterns tend to be random and so inclusion of some of them into the texture calculation does not change the type of texture found. If an MQ factor had been available in this study, it would have been possible to exclude such grains from the measurements. Alternatively by simultaneous recording of EBSP and an energy dispersive X-ray fluorescence signal, phases could be assigned. Without such additional information it is conceivable that EBSP patterns from other minerals were recorded as quartz and falsified the total texture to a small degree.

\section{CONCLUSIONS}

This study documents the success of using an IQ factor generated by automated analysis of EBSPs to isolate orientation measurements of quartz from measurements of other phases in a polyphase rock. The accuracy of texture analysis performed on isolated measurements is confirmed by previously documented textures of mylonitic quartz. 
This technique will be useful in studying how quartz grains interact with or are affected by other minerals during deformation.

\section{Acknowledgements}

We are appreciative for access to the facilities on for support to the Center for Materials Science at Los Alamos National Laboratory and for help and discussions with Stewart Wright (now at TexSEM Laboratories). Financial support from IGPP-LANL and NSF (grants EAR 9104605 and EAR 94-17580) are gratefully acknowledged.

\section{References}

Adams, B.L., Wright, S.I. and Kunze, K. (1993). Orientation imaging: the emergence of a new microscopy. Metallurgical Transactions 24A, 819-833.

Barber, D.J. and Wenk, H.-R. (1991). Dauphiné twinning in deformed quartzites: implications of an in situ TEM study of $\alpha-\beta$ phase transformation. Physics and Chemistry of Minerals 17, 492-502.

Drechsler, L.P., Feldmann, K., Frischbutter, A. and Walther, K. (1988). Neutronographic fabric analysis of quartz in naturally deformed gneiss. Textures and Microstructures 8\&9, 737-750.

Erskine, B.G. and Wenk, H.-R. (1985). Evidence for Late Cretaceous crustal thinning in the Santa Rosa mylonite zone, southern California. Geology 13, 274-277.

Gleason, G.C., Tullis, J. and Heidelbach, F. (1993). The role of dynamic recrystallization in the development of lattice preferred orientations in experimentally deformed quartz aggregates. Journal of Structural Geology 15, 1145-1168.

Helming, K., Wenk, H.-R., Choi, C.S. and Schäfer, W. (1994). Description of quartz textures by components. Examples from metamorphic rocks. In: Textures in Geological Materials (H.J. Bunge et al., Eds.). Deutsch. Gesell. Metallkunde, Oberursel, Germany, 303-325.

Illingworth, J. and Kittler, J. (1988). A survey of the Hough transform. Computer Vision, Graphics and Image Processing 44, 87-116.

Jessell, M.W. and Lister, G.S. (1990). A simulation of the temperature dependence of quartz fabrics. In: Deformation Mechanisms, Rheology and Tectonics (R.J. Knipe and E.H. Rutter, Eds.). Geological Society Special Publication 54, 353-362.

Kunze, K., Adams, B.L., Heidelbach, F. and Wenk, H.-R. (1994). Local microstructural investigations in recrystallized quartzite using orientation imaging microscopy. Proc. ICOTOM 10, Mater. Sci. Forum 157-162, 1243-1250.

Kunze, K., Adams, B.L., Heidelbach, F. and Wenk, H.-R. (1993). Local microstructural investigations in recrystallized quartzite using orientation imaging microscopy. International Conference on Textures in Materials 10, 1243-1249. ClausthalZellerfeld, Trans Tech Publications.

Kunze, K., Heidelbach, F., Wenk, H.-R. and Adams, B.L. (1994). Orientation imaging microscopy of calcite rocks. In: Textures in Geological Materials (H.J. Bunge et al., Eds.). Deutsch. Gesell. Metallkunde, Oberursel, Germany, 127-146.

Lutterotti, L., Matthies, S., Wenk, H.-R., Schultz, A.J. and Richardson, J.W. (1997). Combined texture and structure analysis of deformed limestone from time-of-flight neutron diffraction spectra. J. Appl. Phys. 81 . 
Matthies, S. and Vinel, G.W. (1993). On some methodical developments concerning calculations performed directly in orientation space. 10th International Conference on Textures in Materials, 1641-1646. Clausthal-Zellerfeld, Trans Tech Publications.

Schmid, S. and Casey, M. (1986). Complete fabric analysis of some commonly observed quartz-c-axis patterns. In: Mineral and Rock Deformation: Laboratory Studies (B.E. Hobbs and H.C. Heard, Eds.). Geophysical Monograph 36, 263-286.

Schmidt, N.H. and Olesen, N.Ø. (1989). Computer-aided determination of crystallattice orientation from electron-channelling patterns in the SEM. Canadian Mineralogist 27, 15-22.

Simpson, C. (1984). Borrego Springs-Santa Rosa mylonite zone: A late Cretaceous westdirected thrust in southern California. Geology 10, 8-11.

Tullis, J. and Tullis, T. (1972). Preferred orientation of quartz produced by mechanical Dauphiné twinning: Thermodynamics and axial experiments. In: Flow and Fracture of Rocks (H.C. Heard et al., Eds.). Geophysical Monographs 16, 67-82.

Wenk, H.-R. and Pannetier, J. (1990). Texture development in deformed granodiorites from the Santa Rosa mylonite zone, southern California. Journal of Structural Geology 12, 177-184.

Wenk, H.-R. (1994). Preferred orientation patterns in deformed quartzites. In: Reviews in Mineralogy Vol. 29, Silica Minerals (Heaney et al., Eds.), 177-208. Mineral. Soc. Amer., Washington DC.

Wenk, H.-R., Canova, G. and Y. Brechet (1997). A deformation-based model for recrystallization. Acta Mater. (in press).

Wenk, H.-R., Canova, G., Molinari, A. and Kocks, U.F. (1989). Viscoplastic modeling of texture development in quartzite. Journal of Geophysical Research 94, 1789517906.

Wenk, H.-R., Matthies, S. and Donovan, J. (1996). BEARTEX, a windows-based program system for quantitative texture analysis. In: Textures of Materials, Proc. ICOTOM 11 (Z. Liang, L. Zuo and Y. Chu, Eds.), 212-217, Intern. Academic Publ., Beijing.

Wright, S.I. (1992). Individual Lattice Orientation Measurements: Development and Application of a Fully Automatic Technique. Ph.D., Yale University.

Wright, S.I. (1993). A review of automated orientation imaging microscopy (OIM). Journal of Computer-Assisted Microscopy 5, 207-221.

Wright, S.I. and Adams, B.L. (1992). Automatic analysis of electron backscatter diffraction patterns. Metall. Trans. A23, 759-767. 